\title{
Labor force diversity and new firm formation
}

\author{
Mikaela Backman ${ }^{1}$. Janet E. Kohlhase ${ }^{2}$ (D)
}

Received: 14 January 2021 / Accepted: 12 October 2021 / Published online: 21 November 2021

(c) The Author(s), under exclusive licence to Springer-Verlag GmbH Germany, part of Springer Nature 2021

\begin{abstract}
Many countries have experienced increases in the diversity of their labor forces. Our paper examines one such country-Sweden - and relates the diversity of the local labor force, in terms of demography, culture, education, occupation and industry, to new firm formation. We measure diversity using entropy measures that account for a wider range of differences than is typically used. Our empirical analysis finds a positive relationship between diversity of the labor force, in terms of demography, culture and education, and the rate of new firm formation. Our results add to the literature on the workings of agglomeration economies in urban growth through variations in human capital, information spillovers and innovation.
\end{abstract}

JEL Classification $\mathrm{R} \cdot \mathrm{R} 3 \cdot \mathrm{L} 2 \cdot \mathrm{J} 1$

\section{Introduction}

As the flow of individuals across country borders increases, women increase their participation in the labor force across many different sectors, and more elderly individuals stay in the labor force, firms and cities are likely to become more diverse in terms of their labor force. Given this background, the goal of our paper is to analyze the impact of the increasing diversity of the work force on new firm formation. Our paper contributes to the current discussions on the economic effects of a diverse labor force.

The role of new firms for economic growth and development is well-documented. New firms contribute to employment growth, productivity growth, and innovations

Janet E. Kohlhase

jkohlhase@uh.edu

Mikaela Backman

Mikaela.Backman@ju.se

1 Centre for Entrepreneurship and Spatial Economics (CEnSE), Jönköping International Business School, P.O. Box 1026, 55111 Jönköping, Sweden

2 Department of Economics, University of Houston, 3623 Cullen Boulevard, Room 204, Houston, TX 77204-5019, USA 
(Baumol 2002; van Praag and Versloot 2007). Moreover, Glaeser et al. (2015) show the positive relation between start-up employment share and long-term employment growth in US cities. Lee (2017) finds positive effects of new firm formation on employment and wages in the wider local economy, benefits that stretch beyond the new firms themselves. Given the importance of new firm formation for regional growth, and the increasing diversity of the labor force in cities, we are motivated to assess how diversity contributes to new firm formation. There are numerous studies focusing on how a diverse labor force in terms of an individual's background, i.e., cultural diversity, effect new firm formation (Audretsch et al. 2010; Cheng and Li 2012; Lee et al. 2004; Niebuhr 2010; Rodríguez-Pose and Hardy 2015). Our paper extends the existing literature by not only examining cultural diversity but also adding the role of labor force diversity in terms of demography, education and occupation to the analysis of new firm formation. Thus, our paper contributes to the literature by adding more dimensions to the role of diversity. Our work here complements work we have done at the individual firm level on the role of diversity on firm survival (Backman and Kohlhase 2020).

The empirical design uses an aggregate approach where the effect of diversity on the rate of new firm formation at the municipal level is analyzed. ${ }^{1}$ The aggregate approach allows us to capture the effect of the external environment on the formation of new firms. Related work by Andersson et al. (2019) also looks at new firm formation across Swedish municipalities, but does not focus as we do on diversity. Our results show the importance of diversity at the local level: we find that diversity in terms of demography, culture and education have a positive association with the rate of new firm formation. All in all, the results highlight the benefits of having a diverse set of inhabitants in terms of background, age (experience), gender and education in terms of new firm formation. These relationships are likely to work through many channels. First, a more heterogeneous set of inhabitants may create an economic environment where ideas are created and transmitted. Second, a diverse population may create a tolerant atmosphere attractive to innovative and human capital-rich individuals. Third, the probability that any individual will see an economic opportunity as a profitable venture may increase if a region is comprised of many different sets of individuals. Fourth, by having a more diverse population more economic opportunities for niched services and products may be produced. We thereby argue that a heterogeneous external labor force is beneficial for the formation of new firms.

The remainder of the paper is organized as follows: Sect. 2 covers the theoretical arguments for why diversity may influence new firm formation. Section 3 covers the estimation method, description of variables, and empirical results. Section 4 concludes the paper.

\footnotetext{
1 Sweden is divided into 290 regions termed municipalities (kommun). The municipalities are local governments that provide services and collect taxes. They are analogous to what in the US are called consolidated city-counties.
} 


\section{Diversity and entrepreneurship}

Locations differ substantially regarding the resources that can be accessed but also the composition, dispersion, and turnover of these resources. Thus, it is not only the scale but also the scope of factors that matter. A heterogeneous labor force in a region can both directly and indirectly relate to the establishment of new firms. The knowledge spillover theory of entrepreneurship focuses on the entrepreneur and his/her ability to exploit new knowledge that can be utilized to form a new firm. Knowledge spillovers can arise through incumbent firms and knowledge creating organizations (such as universities) and if the new knowledge is not internalized there is scope for an entrepreneur to close the knowledge gap and start a new firm. Thus, knowledge spillovers are an important determinant for creating new firms (Audretsch and Lehmann 2005; Acs et al. 2009). Following this, a higher level of knowledge accessed in the region and its diversity can be utilized by entrepreneurs and thereby lead to a higher level of new firm formation (Bishop 2012, 2019).

Even though the stock and diversity of the local knowledge base are important to the creation of new firms, equally important are the recipients of new ideas. A diverse group of individuals in terms of individual characteristics, both inherited and learned abilities, is more likely to value these ideas differently. The probability that some individuals see the new ideas as means of profitable ventures is increased (Jacobs 1961). Hence, the relation between diversity and new firm formation may work through the increased diversification of the valuation of new ideas and new knowledge. A more diverse set of individuals through diversified experiences, backgrounds, capabilities, interest, and skills may increase the probability that an individual will value the idea as profitable and commercially exploit the idea through a new venture (Audretsch et al. 2010). Desrochers (2001) strongly argues for the positive influence of diversity on start-ups since individuals of diverse background are capable of creating new and novel combinations of existing knowledge and technology that is manifested through new firms. Several studies support these hypotheses, where a positive relationship is established between labor force diversity and the level of regional innovativeness as reflected in measures such as patents (Lee 2001), new firm formation (Audretsch et al. 2010; Lee et al. 2004; Zhang 2020), and regional R\&D activities (Niebuhr 2010).

The variety found in a region's inhabitants further stimulates the demand for products and services. Heterogeneity in people may lead to diverse demand where new firms can enter and find a market share not occupied by incumbent firms (Bae and Koo 2009). Similar arguments are used to analyze how cultural/ethnical diversity relates to entrepreneurship. Individuals with foreign backgrounds may be more likely to start a new firm due to discrimination, lack of language proficiency and lack of networks and business contacts (Yoon 1997). The aforementioned factors lie at the individual level but can also be translated to the regional level where the share of immigrants has been found to be positively associated with the rate of new firm formation (Cheng and Li 2012; Kirchhoff et al. 2002; Reynolds et al. 1995; Saxenian 2000; Sun et al. 2019). The authors emphasize the increased demand for more 
niched services and products as the labor force becomes more diverse (pull factors) as well as the lack of employment possibilities for immigrants (push factors).

Indirectly, a diverse labor force may be associated with the creation of new firms as the diversity may positively affect the rate of information exchange and flow, facilitating innovation and start-ups (Lee et al. 2004; Reynolds et al. 1995). Locations that are open and diverse may be attractive to able individuals leading to a higher level of innovation and creativity, actions that are highly correlated with the births of firms. In such diverse environments innovation and new ideas may also be promoted and valued, further increasing the rate of new firm formation (Jacobs 1961). Regions endowed with a diverse population may have low barriers to entry that further accelerates the diversity by attracting individuals with diverse backgrounds (Acs and Megyesi 2009).

It is important to point out that a location that is diverse in terms of its inhabitants could also impose costs on the formation and growth of firms. Homogeneity may have certain advantages. For example, groups of individuals that share a common background, the same cultural norms, and speak the same language have an advantage in co-operation and interaction (Costa and Kahn 2003), thus potentially reducing firm costs. Locations that are heterogeneous in terms of residents may impose burdens on firms that stem from a potential decreased level of civic engagement of the population (Costa and Kahn 2003; Vigdor 2004). These are important considerations not only when initially forming firms but also for firms' future development. In sum, the theories of diversity and firm performance lead us to expect both positive and negative relations between diversity and new firm formation. Ultimately it is an empirical question to see which effect dominates - a question we will next examine.

\section{Empirical design}

Sweden is a heterogeneous country with considerable diversity within its borders. In 2010, approximately one fifth of all children were born in another country or had both parents born in another country. Overall, approximately 19 percent of the Swedish population has a foreign background, and the number is continuously increasing. Sweden has also a long tradition of high labor force participation among women; the female labor force participation rate in 2010 was 60 percent. $^{2}$ As in many other developed countries, the demographic profile among inhabitants is changing so that Sweden has an increased share of older individuals. The legislative and financial incentive structures are encouraging employees to work longer. All these factors create a heterogeneous environment both at the regional level and within firms. In Sweden, the distribution of the demographic profile across space is uneven where for example individuals with a foreign background are more likely to live in metropolitan areas and older individuals are often found in rural areas-patterns shared with many other countries around the world.

\footnotetext{
${ }^{2}$ Based on statistics from Statistics Sweden, www.scb.se and http://data.worldbank.org/indicator/SL. TLF.CACT.FE.ZS, accessed January 2021.
} 
To put the Swedish statistics in perspective it is useful to compare with the US experience. In 2010 about 13 percent of the US population was foreign-born and about 24 percent of children age 17 and younger had at least one foreign-born parent. And like Sweden, individuals with a foreign background are unevenly distributed across the US, with four states having over half of the foreign-born population, about 56 percent. As is true for Sweden, in the US the foreign-born are much more likely to live in metropolitan than rural areas: in 2010 about 84 percent of the foreign-born population lived in large metropolitan areas, and about 16 percent lived in small or non-metro areas. The US labor force participation rate of women was about 58.9 percent (declining from a maximum over 60 percent in 2000), slightly lower than Sweden's. ${ }^{3}$

To empirically test whether there is a relationship between diversity and new firm formation we use a dataset from Statistics Sweden, with restricted public access. We investigate how regional diversity relates to the rate of new firm formation at the municipal level using a fixed-effects model for the period 1993 to 2010.

\subsection{Data and variables}

We construct the new firm formation variable by using firm-level data aggregated to the municipal level. Only firms with economic activity are analyzed for each year, i.e., firms that report value-added taxes (VAT) and/or payroll taxes. A firm is registered as a new firm if a new organization number is identified and the majority of the employees are new, i.e., if they did not work in the firm before the organization number was changed. ${ }^{4}$ New firms that arise due to division of firms or mergers of already existing firms where the majority of employees are the same as previous years are not registered as new firms. Thus, spin-offs and/or mergers are registered as new firms given that they substantially change their composition of employees. By using these criteria only new active establishments given the employee composition are included in the sample.

The number of new firms is standardized by the number of individuals in the labor force (defined as number of inhabitants aged 18-65 years) following the labor market approach suggested by Audretch and Fritsch (1994). ${ }^{5}$ The labor market approach is justified by the fact that mostly individuals and not firms create new firms. In

\footnotetext{
${ }^{3}$ Based on statistics from several US sources including the US Census, Brookings Institute, the St. Louis Fed, and The Immigration Policy Institute. In order presented above http://www.census.gov/prod/ 2012pubs/acs-19.pdf; http://www.migrationpolicy.org/article/frequently-requested-statistics-immigrantsand-immigration-united-states-0\#7; http://research.stlouisfed.org/fred2/series/LNS11300002; https:// www.brookings.edu/research/immigrants-in-2010-metropolitan-americaa-decade-of-change/. Accessed January 11, 2021.

4 The two following conditions are met: (number of common employees year $t$ and $t+1) /($ number of employees in $t+1)<0.5$ and (number of common employees year $t$ and $t+1) /($ number of employees in t) $<0.5$.

5 The ecological approach where the number of new firms is standardized by the total number of firms in a municipality has also been tested with similar results.
} 
addition, new firms are often established close to the individuals' residences (Evans and Jovanovic 1989; Mueller and Morgan 1962; Sorenson and Audia 2000).

We choose to measure diversity of the labor force using various entropy measures. Entropy measures have many features which make them suitable for measuring diversity. One feature is the decomposable nature of the indexes and perhaps more important is the weighting structure. The weights in an entropy measure decrease in absolute terms as the share in a category increase. The entropy measure differs from the often used Herfindahl-index. A small increase in the number of individuals in the category that constitutes the majority makes a small difference for the entropy value while a small increase in an under-represented category increases the entropy value. A Herfindahl index would be more sensitive, and change in value, if there were a small change in the number of individuals in the largest category and not sensitive to the under-represented categories (Jacquemin and Berry 1979; Kwoka 1985). The entropy measure is also more responsive to changes within a given group than are other measures; the entropy measure grows higher as diversity increases given a fixed number of individuals (White 1982). In the following we set-up the diversity measures at the municipal level and define the entropy measures using the framework as described in Backman and Kohlhase (2020).

The first variable describing municipal demographic diversity considers the dimensions of gender and age of the inhabitants. Individuals are separated into six age (16-25, 26-35, 36-45, 46-55, 56-65, <65) and two gender categories. An entropy measure (Theil index) is used to define the diversity and is presented in Eq. (1):

$$
\text { Demographic diversity }_{m}=-\sum_{c=1}^{12} \frac{i_{c}}{i_{m}} \ln \left(\frac{i_{c}}{i_{m}}\right)
$$

where $i$ represent the number of inhabitants, $m$ represents the municipality and $c$ represents the category that an individual belongs to depending on gender and age. A more diversified municipality has a higher entropy value. The distribution of this entropy value ranges from zero to $\ln (c)$.

To capture the ethnic composition in the municipality we use the same reasoning as in the index for the demographic composition and construct a Theil index which measures the cultural diversity (Cultural diversity). We are not able, due to data limitations, to construct this index based on the inhabitant's specific country of origin but countries are rather classified into ten regional groups: Sweden, Nordic countries (except Sweden), EU15 (except Denmark, Finland and Sweden), Europe (except EU15 and the Nordic countries), Africa, North America, South America, Asia, Oceania, and Russia. Our measure of municipal ethnic diversity is expressed in Eq. (2).

$$
\text { Cultural diversity }_{m}=-\sum_{c=1}^{10} \frac{i_{c}}{i_{m}} \ln \left(\frac{i_{c}}{i_{m}}\right)
$$

where $i$ represent the number of inhabitants, $m$ represents the municipality and $c$ represents the category that an individual belongs to depending on the region of origin. A municipality with a larger mix of individuals based on their region of origin has a higher entropy value. The distribution ranges from zero to $\ln (c)$. 
Labor force diversity is also captured by the composition of the inhabitants' educational profiles (Education diversity) and occupation profiles (Occupation diversity). They are calculated by summing two diversity measures: "unrelated variety" and "related variety." Unrelated variety is measured at a higher aggregation level compared to the related variety and gives an indication of the variety of different types of education or occupational orientation. Related variety is a weighted sum of entropy used at the disaggregated level within each higherlevel aggregation, showing the diversity within education or occupational groups (Frenken et al. 2007; Wixe \& Andersson 2016; Jacquemin \& Berry 1979). The measurements of the unrelated (UV) and related variety (RV) are presented in Eqs. (3) and (4).

$$
\begin{gathered}
\mathrm{UV}_{m}=-\sum_{g=1}^{G} P_{g} \ln \left(P_{g}\right) \\
\mathrm{RV}_{m}=\sum_{g=1}^{G} P_{g} H_{g} \quad \text { where } H_{g}=-\sum_{i \in S_{g}} \frac{P_{i}}{P_{g}} \ln \left(\frac{P_{i}}{P_{g}}\right)
\end{gathered}
$$

where $G$ is the number categories at the higher aggregation level $g$ (two-digit), $P_{g}$ is the share of total employment at the higher level in the municipality $m, S_{g}$ is the number of categories of education and/or occupation at the lower level of aggregation, $P_{i}$ is the employment share at the finer aggregation level $i$ (three-digit) within each two-digit level and $H_{g}$ is the distribution of employees between the three-digit level $i$ within each two-digit level. Due to the decomposable nature of the entropy measure the unrelated and related variety can be summed to form the total education or occupation diversity for each municipality $m$. That is we define

$$
\begin{aligned}
& \text { Education diversity }{ }_{m}=\mathrm{UV}_{m}+\mathrm{RV}_{m} \\
& \text { Occupation diversity }_{m}=\mathrm{UV}_{m}+\mathrm{RV}_{m}
\end{aligned}
$$

where educational categories are used in Eq. (5) and occupational categories are used in Eq. (6). The variable Education diversity is then the weighted average diversification within each education category plus the diversification across education categories and Occupation diversity is interpreted similarly except using occupation categories (Jacquemin and Berry 1979; Theil 1972). Thus, by adding the two terms "unrelated variety" and "related variety." we get the total diversity within the municipality for each of our diversity measures Education diversity and Occupation diversity. Higher values indicate more diversification.

Diversity can also be measured through the industrial structure of employment. The diversity of the municipal industrial structure is represented by the sum of the two entropy measures: unrelated and related variety (Industry diversity) described in Eqs. (3) and (4). Unrelated variety is measured at the two-digit SIC code level and related variety is a weighted sum of entropy at the five-digit level within each 
two-digit industry. The industry index is based on 60 categories at the two-digit level and 777 categories at the five-digit level. That is

$$
\text { Industry diversity }_{m}=\mathrm{UV}_{m}+R V_{m}
$$

To further capture the diversity within a location, we use the share of inhabitants born outside of Sweden (Share of immigrants) and use the variable in our empirical work. The variable has been used in previous studies and we use it to capture other dimensions of regional diversity than implied by the entropy measures. The entropy measures and immigrant variables are constructed using population registrar data aggregated to the municipal level.

We also construct a set of control variables to use in the regression analysis. New firms may arise in environments that are booming and/or already have a large demand, and these are captured by including variables that measure the change in demand ( $\Delta$ demand) and the economic size of the municipality (Market potential) (Armington and Acs 2002; Sutaria and Hicks 2004b; van Stel and Suddle 2008). Both variables are measured using actual wages earned by individuals in each municipality. The variable Market potential is based on the distance-discounted wages in a hierarchy of geographical regions as they relate to a given municipality (See Table 1, footnote b). Another labor market factor is the unemployment rate (Unemployment rate) that can have an ambiguous effect on new firm rate formation. It can work as a pull factor since the individual does not have another occupation. It can, however, also work as a push factor since a high rate of unemployment may indicate that the economy is suffering and might have a lower demand and market potential (Audretsch et al. 2001; Binks and Jennings 1986; Parker 2004; Sutaria and Hicks 2004a). The industrial structure in a municipality affects the new firm formation rate where locations with on average larger firms, in terms of number of employees, $(M E S)$ have a hampering effect. A larger number of small establishments can also be an indicator of diversification, following Reynolds et al. (1995). Local competition (Firms per capita) might work as a growth stimulus since local it fosters innovation and information spillovers. Further, an increase in the number of firms given the population should facilitate knowledge spillovers (Ciccone and Hall 1996; Porter 1990).

Table 1 gives a short description of the chosen variables and summary statistics over the time period 1993-2010. There is a total of 4,760 observations (17 years for each of 280 municipalities). There are currently 290 municipalities in Sweden but due to changes over time only 280 municipalities can be traced over the chosen time period.

\subsection{Estimation method and empirical results}

Using a balanced panel, we estimate new firm formation using a fixed-effects framework where we allow entity and time fixed effects. Our estimation model predicting new firm formation is described in Eq. (8): 


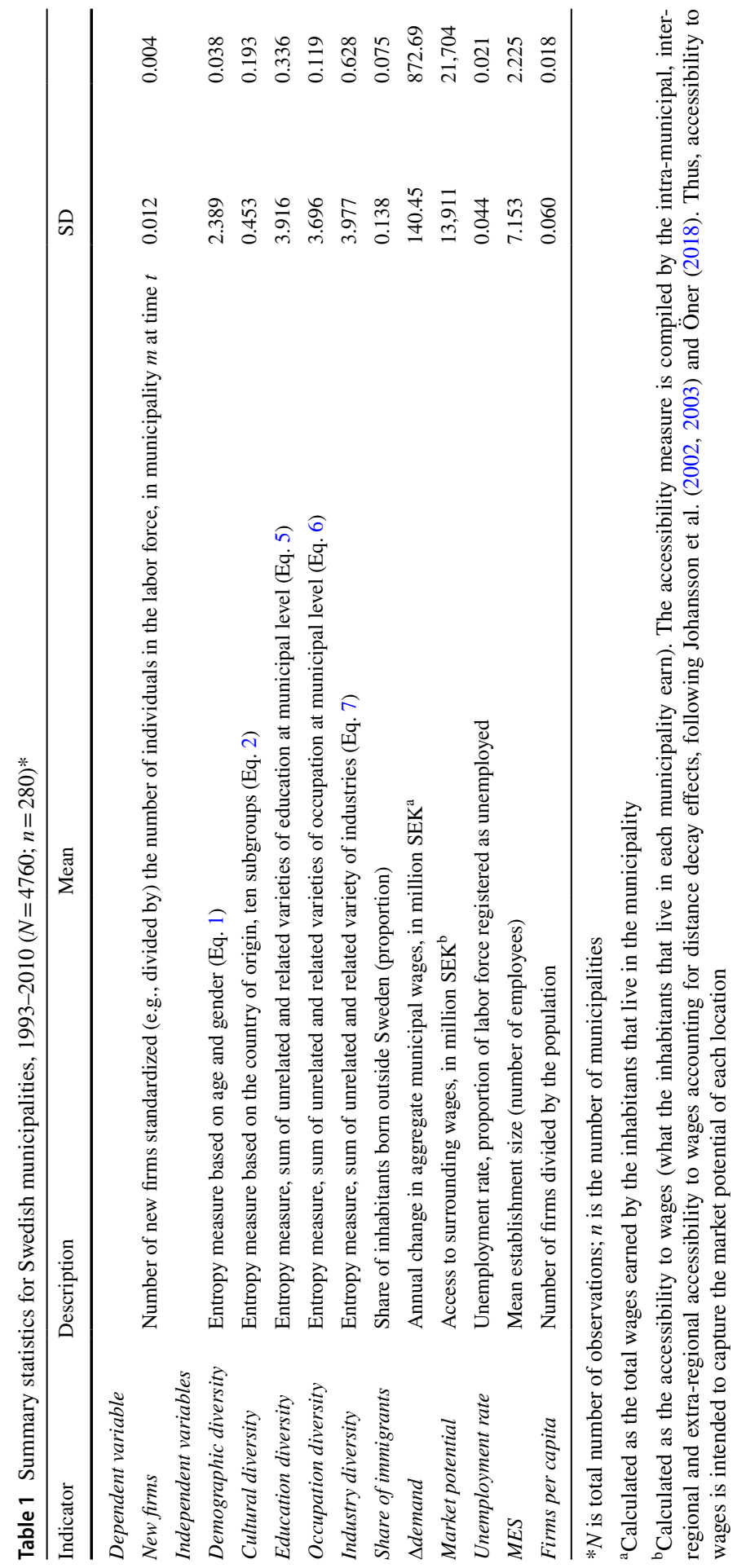




$$
\ln N F F_{m t}=\beta_{o}+\text { Diversity }_{m t}^{\prime} \gamma+X_{m t}^{\prime} \delta+\alpha_{m}+\gamma_{t}+u_{m t}
$$

where $N F F$ is standardized new firm formation (in natural logs), Diversity ${ }_{m t}^{\prime}$ is a vector of variables that measures the diversity of inhabitants in the municipality $m$ (i.e., Demographic diversity, Cultural diversity, Education diversity, Occupation diversity, Share of immigrants) as well as the diversity of local industry (Industry diversity) at time $t . X_{m t}^{\prime}$ represents a vector of control variables related to municipal characteristics $m$ that can vary over time $t$, described in the previous section. $\beta_{o}$ is the intercept, $\gamma$ and $\delta$ are vectors of parameters to be estimated. $\alpha_{m}$ is the time-constant unobserved municipality fixed effect; $\gamma_{\mathrm{t}}$ is the time fixed effect and $u_{m t}$ is the idiosyncratic error term. In our estimation, we cluster the errors at the local labor market (LLM) level. The LLMs are defined by Statistics Sweden based on commuting patterns and are functional regions that form a common market for labor, housing and services. Local labor markets are composed of one or more municipalities and are typically larger in land area than are the municipalities. There are 76 local labor markets made up of the 290 municipalities. As such, municipalities within the same LLM share common characteristics, challenges, and opportunities, hence the reason we cluster at the LLM level.

Table 2 presents our basic results about the determinants of new firm formation with particular focus on the role of our measures of diversity-Demographic diversity, Cultural diversity, Education diversity, Industry diversity and Share of immigrants - and shows all control variables. Table 3 illustrates estimations using Occupation diversity where we show only the coefficient on the diversity variables while the other regressors are suppressed. However, the signs and significance of the suppressed variables are similar across the different estimations. The reason why Occupation diversity is estimated separately is the different time period covered (2002-2010) as the occupational data only started to be registered in 2002.

The results in Table 2 show a positive relationship between diversity and new firm formation at the municipal level. We find that our three measures of diversity of the inhabitants in the municipality (Demographic diversity, Cultural diversity and Education diversity) have a positive effect on new firm formation.

Our results imply that changing regional Demographic diversity (in terms of age and gender) by one standard deviation will lead to a change in the new firm formation by approximately 5.5 per cent. ${ }^{6}$ Having a diverse set of individuals regarding the age composition can create positive effects as different age cohorts complement each other in the knowledge they possess. Similar findings are found at the firm-level by Lazear and Gibbs (2011). Older individuals have naturally gained more experience and learning by doing while younger individuals are more prone to adapt to changes and have a more up to date education. The possible increased knowledge exchange may spur new firms. The intergenerational aspect is, however, hard to capture by the diversity measure and should be further analyzed in future studies. Another aspect of the age composition is the so-called "grey entrepreneurship" (where older individuals become entrepreneurs) which is a growing tendency in many countries (Weber and Schaper 2004; Kautonen et al. 2011). As firms and

\footnotetext{
$\overline{{ }^{6} \text { For a } \log \text {-lin specification } \ln y}=a+b x, \% \Delta y=100 \% \cdot b \cdot(1 \mathrm{SD} \Delta x)$.
} 
Table 2 Diversity and new firm formation, fixed-effects estimation, 1993-2010

Table 3 Occupation diversity and new firm formation, fixedeffects estimation, 2002-2010
Dependent variable: new firm formation, standardized-(ln)

\begin{tabular}{|c|c|c|}
\hline & (1) & (2) \\
\hline Demographic diversity & $\begin{array}{l}1.485 * * \\
(0.291)\end{array}$ & $\begin{array}{l}1.477 * * \\
(0.289)\end{array}$ \\
\hline Cultural diversity & $\begin{array}{l}0.237 * * \\
(0.099)\end{array}$ & - \\
\hline Education diversity & $\begin{array}{l}0.081 * * \\
(0.021)\end{array}$ & $\begin{array}{l}0.080 * * \\
(0.019)\end{array}$ \\
\hline Industry diversity & $\begin{array}{l}-0.018 \\
(0.020)\end{array}$ & $\begin{array}{l}-0.017 \\
(0.026)\end{array}$ \\
\hline Share of immigrants & - & $\begin{array}{l}0.515 * * \\
(0.247)\end{array}$ \\
\hline$\Delta$ demand & $\begin{array}{l}2.70 \mathrm{e}-6^{* *} * \\
(2.67 \mathrm{e}-6)\end{array}$ & $\begin{array}{l}2.59 \mathrm{e}-6^{* *} \\
(9.36 \mathrm{e}-6)\end{array}$ \\
\hline Market potential (ln) & $\begin{array}{l}-0.238 * * \\
(0.049)\end{array}$ & $\begin{array}{l}-0.240 * * \\
(0.049)\end{array}$ \\
\hline Unemployment rate & $\begin{array}{l}0.009 \\
(0.359)\end{array}$ & $\begin{array}{l}0.023 \\
(0.359)\end{array}$ \\
\hline$M E S$ & $\begin{array}{l}-0.043^{* *} \\
(0.008)\end{array}$ & $\begin{array}{l}-0.043^{* *} \\
(0.008)\end{array}$ \\
\hline Firms per capita & $\begin{array}{l}8.715 * * \\
(0.724)\end{array}$ & $\begin{array}{l}8.687 * * \\
(0.787)\end{array}$ \\
\hline Constant & $\begin{array}{l}-5.009 * * \\
(1.055)\end{array}$ & $\begin{array}{l}-4.930 * * \\
(0.851)\end{array}$ \\
\hline$N$ & 4760 & 4760 \\
\hline$n$ & 280 & 280 \\
\hline$F$-value & 258.80 & 274.55 \\
\hline$R^{2}$ overall & 0.42 & 0.40 \\
\hline$R^{2}$ within & 0.64 & 0.64 \\
\hline
\end{tabular}

Standard errors in parentheses, clustered at the local labor market level. The estimations include FE for entities (municipalities) and years

**Significant at one per cent, *significant at five per cent

Dependent variable: new firm formation, standardized-(ln)

(1) (2)

\begin{tabular}{lll}
\hline Occupation diversity & -0.021 & -0.019 \\
& $(0.056)$ & $(0.043)$
\end{tabular}

Standard errors in parentheses, clustered at the local labor market level. The estimations include FE for entities (municipalities) and years. The estimations include the same regressors as in Table 2 except we substitute Occupation diversity for Industry diversity. In the case of Occupation diversity only the years 2002 to 2010 can be used due to data restrictions. Number of observations: 2240 (280 municipalities)

**Significant at one per cent, *significant at five per cent 
especially new firms make use of new markets to fill demand gaps, an important aspect of demographic diversity is the possibility that it provides the impetus to create demand for new products and hence new markets. Individuals of different ages and different genders may have different tastes and incomes and could therefore generate a greater variety of demands.

Increasing Cultural diversity by one standard deviation is associated with an increase in new firm formation of about 5.3 percent. The substitute measure for ethnic diversity, the Share of immigrants also positively relates to the rate of new firm formation. Increasing Share of immigrants by one standard deviation is associated with an increase in new firm formation of about five percent. The finding closely corresponds to the 5.5 percent predicted increase in new firm formation when changing our entropy measure of ethnic diversity, Cultural diversity, by one standard deviation. Both of our proxies for ethnic diversity are positively associated with new firm formation and confirm other studies that examine cultural diversity (Audretsch et al. 2010; Cheng and Li 2012; Niebuhr 2010). It is plausible that individuals with a foreign background have a consumption basket, both of goods and experiences, which differ from the native population. Thus, to have a large share of inhabitants with a foreign background may enable the creation of new niche markets, where entrepreneurs can fill the gap. Individuals with a foreign background may also see opportunities in the new country by bringing in products and services from their native country to test if there is a demand for the products. Another reason is the lack of employment opportunities that might exist for individuals with a foreign background due to for example language barriers, discrimination, or lack of networks. The lack of employment opportunities may push the individuals to become necessity-based entrepreneurs.

Increasing Education diversity by one standard deviation is associated with an increase in new firm formation of 2.8 percent. This is an interesting finding as it points to the importance of having a diverse knowledge base in the region which may also induce knowledge exchange. Having inhabitants with more diverse educational backgrounds enables them to view the same market from various perspectives. Thus, following the same reasoning as Jacobs (1961), it is more likely that in an environment with more diverse educational backgrounds, the group may be able to distinguish more opportunities than if everyone had the same educational background. Having inhabitants with various levels of educational training may facilitate already established firms and entrepreneurs to find suitable employees, the perhaps most important input to a firm. Such matches might further foster new firm formation. We understand that educational diversity might also differ across sectors, as presented by Bishop and Shilcof (2017) where the diversity tends to have a stronger relationship within the service sector. We are not able to address sectorial differences here and defer the topic to future research. In assessing our findings about education diversity, we note that prior research has established that human capital is an important factor for new firm formation. Thus our contribution is to not only show that the stock of education matters to new firm formation but also that the composition of the stock that is vital.

Our industry diversity measure (Industry diversity), is intended to capture Jacobs externalities (where knowledge spillovers emerge from outside a firm's core industry 
and enhance a firm's performance or enhance the conditions for new firm formation). However, the coefficient is insignificant. Our finding may be due to data limitations: since there is no information regarding which core sector a new firm belongs and in which municipalities some sectors are over-represented. Therefore, the variable Industry diversity may not fully capture the extent of knowledge spill-overs.

Turning now to Table 3-which captures diversity in terms of occupational categories-we find that (Occupation diversity) is also insignificant. Occupation diversity is only measured for 2002 to 2010 (due to data restrictions) but it is not the time period as such that is driving the results. Thus, the occupational diversity does not seem to create beneficial conditions for new firm formation at the municipal level.

The signs of the control variables' coefficients follow normal expectations where an increase in demand ( $\Delta$ demand) or an increase in firm intensity (Firms per capita) is positively related to new firm formation while the mean establishment size $(M E S)$ is negatively associated with new firm formation. The only unexpected result is the negative coefficient on the market size variable (Market potential). The result may be driven by the fact that the rate of new firm formation is high in many small municipalities in the north of Sweden.

\subsection{Sensitivity analysis: alternative specifications}

We next check the sensitivity of our results to changing various aspects of our approach: including controlling for potential endogeneity by using instrumental variables or splitting the sample, checking the sensitivity of our results to the level of spatial aggregation, trying different definitions of the dependent variable and examining the error structure.

To account for potential endogeneities in two of our main diversity measures, Cultural diversity and Share of immigrants, we use an instrumental variable approach in our first sensitivity analysis. We use the share of immigrants in 1990 - a time period before the start of our data series - as an instrument. The validity of the instrument is driven by Swedish policy changes. In 1991, the government changed the rules allowing immigrants to settle wherever they wanted; before this change refugees were allocated by the government to different municipalities. The relevance condition is verified by significant results in the first-stage equation and by high $F$-values (all are above 10) indicating that the null hypothesis of weak instruments can be rejected. Similar instrument has been used in Dahlberg et al. (2012).

Since the instrument is time-invariant we are unable to run a fixed-effect instrument estimation. Therefore, in Table 4 we rely on random-effect estimation (RE) in the IV tests and present 2SLS and an Hausman-Taylor estimation results for comparison. We only show the results for the diversity variables, not the control variables. Columns (1) and (2) confirm the earlier results from Table 2 for the all the diversity measures based on the RE instrument approach. In contrast, the 2SLS and the Hausman-Taylor results diverge somewhat from the results in Table 2. While both alternative estimation techniques preserve the finding of the positive relation between cultural diversity (and share immigrants) and new firm 


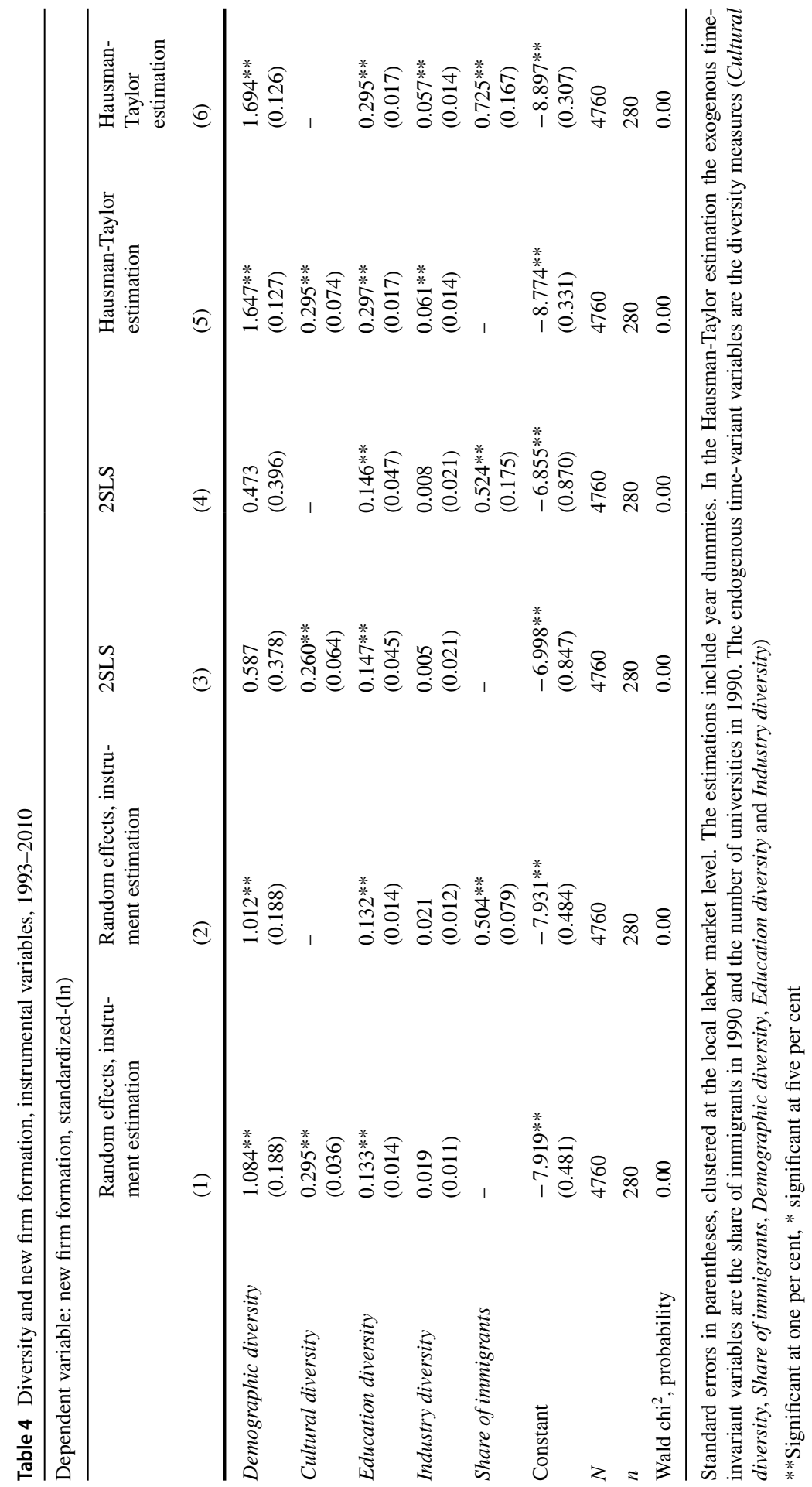


Table 5 Diversity and new firm formation, fixed-effect estimation splitting the sample of municipalities into (1) municipalities with a high share of immigrants in 1990 (above the average) and those with a low share (below average), and (2) into urban and rural municipalities, 1993-2010

\begin{tabular}{lllll}
\hline Dependent variable: New firm formation, standardized-(ln) & & \\
\hline & $\begin{array}{l}\text { High share of immi- } \\
\text { grants in } 1990\end{array}$ & $\begin{array}{l}\text { Low share of immi- } \\
\text { grants in 1990 }\end{array}$ & Urban & Rural \\
& $(1)$ & $(2)$ & $(3)$ & $(4)$ \\
\hline Demographic diversity & $0.756^{* *}$ & $1.350^{* *}$ & 0.267 & $1.425^{* *}$ \\
& $(0.325)$ & $(0.265)$ & $(0.316)$ & $(0.260)$ \\
Cultural diversity & $0.464^{* *}$ & -0.003 & 0.033 & $0.196^{*}$ \\
& $(0.108)$ & $(0.102)$ & $(0.109)$ & $(0.100)$ \\
Education diversity & $0.214^{* *}$ & $0.069^{* *}$ & 0.048 & $0.089^{* *}$ \\
& $(0.059)$ & $(0.022)$ & $(0.025)$ & $(0.027)$ \\
Industry diversity & -0.011 & -0.028 & 0.010 & 0.010 \\
& $(0.026)$ & $(0.024)$ & $(0.026)$ & $(0.024)$ \\
Share of immigrants & $0.859^{* *}$ & 0.222 & 0.064 & $0.646^{* *}$ \\
Constant & $(0.212)$ & $(0.260)$ & $(0.215)$ & $(0.234)$ \\
& $-4.156^{* *}$ & $-5.430^{* *}$ & $-5.344^{* *}$ & $-6.130^{* *}$ \\
$N$ & $(1.163)$ & $(1.171)$ & $(1.171)$ & $(1.275)$ \\
$n$ & 1649 & 3111 & 1479 & 3281 \\
$F$-value & 97 & 183 & 87 & 193 \\
$R^{2}$ overall & 132.43 & 228.06 & 92.94 & 228.94 \\
$R^{2}$ within & 0.27 & 0.65 & 0.61 & 0.73 \\
\hline & 0.60 & 0.66 & 0.63 & 0.65 \\
\hline
\end{tabular}

Standard errors in parentheses, clustered at the local labor market level. The estimations include year dummies. The variables Cultural diversity and Share of immigrants are estimated separately

**Significant at one per cent, *significant at five per cent

formation, there are some differences from the findings in Table 2. We find that Demographic diversity is not significant in the 2SLS estimation shown in columns (3) and (4) and industry diversity becomes significant in the Hausman-Taylor estimation, shown in columns (5) and (6).

In the next table, Table 5, we continue with our alternative specifications and split the sample by share of immigrants in 1990. Splitting the sample allows comparison of new firm formation in municipalities having different degrees of opportunity to employ a diverse set of employees. We split the sample of municipalities into two groups, those above the average share of immigrants in 1990 (High) and those below the average (Low). The variables Demographic diversity and Education diversity show the same relationship across the different samples and also reflects the previous results found in Table 2 (positive effect on new firm formation). What differs across the samples is the relation of Cultural diversity and Share of immigrants where both variables are only significant (positive) in those municipalities that in 1990 had a high share of immigrants. We get the same result when using the median of the share of immigrants in 1990 to divide the sample. 
Table 5 columns (3) and (4) present the results from splitting the sample into urban and rural municipalities. The previous results from Table 2 are again confirmed, but only for the rural municipalities shown in column (4). Thus, the diversity aspect in promoting the rate of new firm formation tends to be more important in the rural context. It should be noted that the variation in diversity measures among the urban municipalities tends to be smaller which could be the reason for the insignificant results. The different results from splitting the sample seem to be counterintuitive as the municipalities with the high share of immigrants in 1990 are the more urban municipalities. The bivariate correlation between the municipalities with a high share of immigrants in 1990 and urban municipalities are approximately 0.4. However, the results may mirror two different processes relating diversity to new firm formation. In the case of rural municipalities, diversity tends to be positively associated with new firm formation, perhaps due to the lower level of diversity in rural areas (especially true for demographic diversity and education diversity). In the case of high/low level of immigrants in 1990 the results may be indicative of a process of path dependence, i.e., immigrants tend to locate where individuals from the same ethnic enclaves are already located, and that process may positively relate to the formation of new firms.

We next conduct a set of specification/sensitivity tests by using different dependent variables as well as examining the error structure. First, we use a shift-share approach to construct alternative measures of the dependent variable and define sector-adjusted rates of new firm formation in each municipality. We find qualitatively similar results to the ones reported in Tables 2 and 3. Other checks are performed pertaining to the error structure. We test for spatial autocorrelation and find none. Using Pesaran and Friedman's test of cross-sectional dependence, we do not reject the null hypotheses of cross-sectional independence (De Hoyos and Sarafidis 2006). Overall, our sensitivity analysis found strong support for our main findings reported in Tables 2 and 3. We tested for and did not find evidence of problems with the assumed error structures.

\section{Conclusions}

As more countries, regions and cities become increasingly integrated, the flows of capital, products and most importantly, individuals, increase. At the same time, a larger share of women is entering occupations and industries that previously have been male dominated. In addition, older individuals remain engaged in the labor market and work longer. All these factors combined lead to economic environments with a more heterogeneous population. Our paper analyses the relation between diversity in the external environment (in term of municipal inhabitants) on the formation of new firms in Sweden. New firms are suitable to analyze since new firms are likely to mirror the capacity of the population to value and assess new ideas as profitable ventures - and these ideas may be realized in the birth of new firms. The focus on diversity and new firms also adds knowledge to the existing literature which normally focuses on more limited measures of diversity than we use here. Concomitant with our in-depth measures of diversity is our ability to examine issues 
at the municipal level. Using a restricted data set allows us to in detail analyze the characteristics of the inhabitants in the municipality.

Our empirical work confirms a positive relationship between a diverse set of inhabitants in terms of region of origin, age (experience), gender and education in a municipality and new firm formation. Thus, we can conclude that having access to a diverse set of individuals, in the local urban economy is beneficial to firms' economic outcomes. Individuals with different backgrounds, age, gender, experience and knowledge may view economic opportunities and new ideas differently. Hence, it is more likely that an individual in a diverse environment (rather than a homogeneous environment) may generate new ideas that could form the basis for a new profitable firm.

The results in this paper also bring some insight into the workings of some of the positive benefits of agglomeration forces as denser and larger cities have greater diversity. The diversity in these cities may contribute to firm formations that have an overall positive impact for the whole region. These diverse regions may become incubators for new firms. Thus, we have been able to add some rigor to Jacobs (1961, p. 448) idea that "lively, diverse, intense cities contain the seeds for their own regeneration."

From a policy perspective, it is important to acknowledge the importance of a diverse economic environment in terms of individuals. And yet we recognize that even though we find a positive relation between diversity at the municipal level and the formation of new firms, diversity might not be the answer or key to the renewal of places.

Given the data and methods we use, as much as we would like to, we are not able to claim to find the causality between diversity and the formation of firms. The diversity measures could be endogenous in the sense that diverse people are more attracted to places that have more new firms opening. Another way to think about potential endogeneity of the diversity measures is to question if a diversity measure itself is responsible for greater firm formation or if there are other variables correlated with the diversity measures that drive firm formation. Results could therefore also signal that, for example, immigrants could be attracted to places that are more business-friendly, especially if those places are also more progressive and accepting of other cultures. To further explore the role of diversity on firm behavior and vice-versa, researchers could compare existing firms with new firms and examine the differences and similarities. Another important topic for future research would be to explore how new form formation and the role of diversity varies by different industrial sectors and across regions, beyond the definition of urban and rural. It is likely that the conditions for the formation, survival and growth of firms may differ across space and type of industry. Other approaches for determining causality are beyond the scope of this paper and are also important future research topics.

Acknowledgements This paper is based on the 61st Presidential Address for the Western Regional Science Association by Professor Janet E. Kohlhase. The talk was delivered virtually on August 12, 2020 as necessitated by the cancellation of WRSA's March 2020 Hawaii meeting due to the corona virus restrictions. The authors are grateful for the comments and suggestions from the discussant Professor Martin Andersson and from the audience. 


\section{References}

Acs ZJ, Braunerhjelm P, Audretsch DB, Carlsson B (2009) The knowledge spillover theory of entrepreneurship. Small Bus Econ 32(1):15-30

Acs ZJ, Megyesi MI (2009) Creativity and industrial cities: a case study of Baltimore. Entrep Reg Dev Int J 21(4):421-439

Andersson M, Koster S (2011) Sources of persistence in regional start-up rates-evidence from Sweden. J Econ Geogr 11(1):179-201. https://doi.org/10.1093/jeg/lbp069

Andersson M, Lavesson N, Partridge M (2019) Local rates of new firm formation: an emprical exploration using Swedish data. IFN Working Paper No. 1290

Armington C, Acs ZJ (2002) The determinants of regional variation in new firm formation. Reg Stud 36(1):33-45

Audretsch DB, Carree MA, Thurik AR (2001) Does entrepreneurship reduce unemployment?: Tinbergen Institute Discussion Paper Series TI 2001-074/3

Audretsch D, Dohse D, Niebuhr A (2010) Cultural diversity and entrepreneurship: a regional analysis for Germany. Ann Reg Sci 45(1):55-85. https://doi.org/10.1007/s00168-009-0291-x

Audretsch DB, Fritsch M (1994) On the measurement of entry rates. Empirica 21(1):105-113. https://doi. org/10.1007/bf01383974

Audretsch DB, Lehmann EE (2005) Does the knowledge spillover theory of entrepreneurship hold for regions? Res Policy 34(8):1191-1202. https://doi.org/10.1016/j.respol.2005.03.012

Backman M, Kohlhase J (2020) Labor force diversity and firm survival. J Reg Sci 60(5):903-928

Bae J, Koo J (2009) The nature of local knowledge and firm formation. Ind Corp Chang 18(3):1-24

Baumol WJ (2002) The free-market innovation machine: analyzing the growth miracle of capitalism. Princeton University Press

Bishop P (2012) Knowledge, diversity and entrepreneurship: a spatial analysis of new firm formation in Great Britain. Entrep Reg Dev 24(7-8):641-660. https://doi.org/10.1080/08985626.2011.617786

Bishop P (2019) Knowledge diversity and entrepreneurship following an economic crisis: an empirical study of regional resilience in Great Britain. Entrep Reg Dev 31(5-6):496-515. https://doi.org/10. 1080/08985626.2018.1541595

Bishop P, Shilcof D (2017) The spatial dynamics of new firm births during an economic crisis: the case of Great Britain. Entrep Reg Dev 29(3-4):215-237

Binks M, Jennings A (1986) Small firms as a source of economic rejuvenation. In: Curran J, Stanworth J, Watkins D (eds) The survival of the small firm. The economics of survival and entrepreneurship, vol 1. Gower, pp 19-37

Cheng S, Li H (2012) New firm formation facing cultural and racial diversity. Pap Reg Sci 91(4):759_ 774. https://doi.org/10.1111/j.1435-5957.2011.00404.x

Ciccone A, Hall RE (1996) Productivity and the density of economic activity. Am Econ Rev 86(1):54-70

Costa DL, Kahn ME (2003) Civic engagement and community heterogeneity: an economist's perspective. Perspect Polit 1:103-111

Dahlberg M, Edmark K, Lundqvist H (2012) Ethnic diversity and preferences for redistribution. J Polit Econ 120(1):41-76

De Hoyos RE, Sarafidis V (2006) Testing for cross-sectional dependence in panel-data models. Stata J 6(4):482-496

Desrochers P (2001) Local diversity, human creativity, and technological innovation. Growth Change 32(3):369-394. https://doi.org/10.1111/0017-4815.00164

Evans DS, Jovanovic B (1989) An estimated model of entrepreneurial choice under liquidity constraints. J Polit Econ 97(4):808-827

Frenken K, Van Oort F, Verburg T (2007) Related variety, unrelated variety and regional economic growth. Reg Stud 41(5):685-697

Glaeser EL, Kerr SP, Kerr WR (2015) Entrepreneurship and urban growth: an empirical assessment with historical mines. Rev Econ Stat 97(2):498-520

Jacobs J (1961) The death and life of great American cities. Random House

Jacquemin AP, Berry CH (1979) Entropy measure of diversification and corporate growth. Journal of Industrial Economics 27(4):359-369

Johansson B, Klaesson J, Olsson M (2002) Time distances and labor market integration. Pap Reg Sci 81(3):305-327 
Johansson B, Klaesson J, Olsson M (2003) Commuters' non-linear response to time distances. J Geogr Syst 5(3):315-329

Kautonen T, Tornikoski E, Kibler E (2011) Entrepreneurial intentions in the third age: the impact of perceived age norms. Small Bus Econ 37(2):219-234

Kirchhoff BA, Armington C, Hasan I, Newber S (2002) The influence of R\&D expenditures on new firm formation and economic growth. Washington and Kansas City: Office of Economic Research, The National Commission on Entrepreneurship and Kauffman Center for Entrepreneurial Leadership

Kwoka JEJ (1985) The Herfindahl index in theory and practise. Antitrust Bull 30(Winter):915-947

Lazear EP, Gibbs M (2011) Personnel economics for managers, 2nd edn. Wiley

Lee SY (2001) Entrepreneurship and business development among African Americans, Koreans, and Jews: exploring some structural differences. In: Cordero-Guzmán HR, Smith RC, Grosfoguel $\mathrm{R}$ (eds) Migration, transnationalization, and race in a changing New York. Temple University Press, pp 258-278

Lee SY, Florida R, Acs Z (2004) Creativity and entrepreneurship: a regional analysis of new firm formation. Reg Stud 38(8):879-891. https://doi.org/10.1080/0034340042000280910

Lee YS (2017) Entrepreneurship, small businesses and economic growth in cities. J Econ Geogr 17:311-343

Mueller E, Morgan JN (1962) Location decisions of manufacturers. Am Econ Rev 52(2):204-217. https://doi.org/10.2307/1910884

Niebuhr A (2010) Migration and innovation: does cultural diversity matter for regional R\&D activity? Pap Reg Sci 89(3):563-585. https://doi.org/10.1111/j.1435-5957.2009.00271.x

Öner Ö (2018) Retail productivity: the effects of market size and regional hierarchy. Pap Reg Sci 97(3):711-736

Parker SC (2004) The economics of self-employment and entrepreneurship. Cambridge University Press

Porter ME (1990) The competitive advantage of nations. Macmillan

Reynolds PD, Miller B, Maki WR (1995) Explaining regional variation in business births and deaths: U.S. 1976-88. Small Bus Econ 7(5):389-407. https://doi.org/10.1007/bf01302739

Rodríguez-Pose A, Hardy D (2015) Cultural Diversity and Entrepreneurship in England and Wales. Environ Plan Econ Space 47(2):392-411. https://doi.org/10.1068/a130146p

Saxenian A (2000) Silicon Valley's new immigrant entrepreneurs working papers. Center for Comparative Immigration Studies, University of California. San Diego

Sorenson O, Audia PG (2000) The social structure of entrepreneurial activity: geographic concentration of footwear production in the United States, 1940-1948. Am J Sociol 106(2):424-462

Sun B, Zhu P, Li W (2019) Cultural diversity and new firm formation in China. Reg Stud 53(10):1371-1384. https://doi.org/10.1080/00343404.2019.1566700

Sutaria V, Hicks DA (2004a) New firm formation: dynamics and determinants. Ann Reg Sci 38(2):241-262. https://doi.org/10.1007/s00168-004-0194-9

Sutaria V, Hicks DA (2004b) New firm formation: dynamics and determinants. Ann Reg Sci 38(2):241-262

Theil H (1972) Statistical decomposition analysis: with applications in the social and administrative sciences. North-Holland

van Praag MC, Versloot PH (2007) What is the value of entrepreneurship? A review of recent research. Small Bus Econ 29(4):351-382. https://doi.org/10.1007/s11187-007-9074-X

van Stel A, Suddle K (2008) The impact of new firm formation on regional development in the Netherlands. Small Bus Econ 30(1):31-47

Weber P, Schaper M (2004) Understanding the grey entrepreneur. J Enterp Cult 12(02):147-164

White AP (1982) A note on market structure measures and the characteristics of markets that they “measure." South Econ J 49(2):542-549. https://doi.org/10.2307/1058503

Wixe S, Andersson M (2016) Which types of relatedness matter in regional growth? Industry occupation and education. Reg Stud. https://doi.org/10.1080/00343404.2015.1112369

Vigdor JL (2004) Community composition and collective action: analyzing initial mail response to the 2000 census. Rev Econ Stat 86(1):303-312. https://doi.org/10.1162/003465304323023822 
Yoon I (1997) On my own: Korean businesses and race relations in America. University of Chicago Press

Zhang C (2020) Skill diversity of cities and entrepreneurship. Reg Stud 54(3):403-414. https://doi.org/ 10.1080/00343404.2019.1699236

Publisher's Note Springer Nature remains neutral with regard to jurisdictional claims in published maps and institutional affiliations. 